\title{
EXPLORING THAI EARLY CHILDHOOD TEACHERS' UNDERSTANDING, BELIEFS AND CONCERNS OF INCLUSIVE EDUCATION: A CASE STUDY OF AN EARLY CHILDHOOD CENTRE
}

\author{
Sunanta Klibthong
}

This study explores early childhood teachers' understanding of inclusion, beliefs and concerns about including young children with disabilities in early childhood programmes in Thailand. The study adopted a qualitative approach of group discussions to gather data from nine early childhood teachers selected from one large preschool enrolling 255 children aged 2-6 years in Bangkok, the capital city of Thailand. Using framework analysis (Ritchie E Spencer, 1994), the findings point to basic conceptualisations of inclusion with beliefs and concerns related to three important themes: (i) cultural and religious issues, (ii) training issues and (iii) type of disability as the main barriers to inclusive education of young children. How to support the teachers to accept all children and practise inclusion in totality have also been discussed.

KEYwORDS: Early Childhood, Inclusive Education, Thai Teachers

\section{INTRODUCTION}

In recent times inclusive education of young children has become a central concern within early childhood education (Reay, 2006). This move is supported by international legislations and conventions on inclusive practice (UN, 1989; UNESCO, 1994, 2000), which advanced arguments that inequalities arising from early childhood educational practices have not been adequately addressed globally. The same can be said about Thailand's early childhood education system. 
Thailand is located in Southeast Asia, bordering the Andaman Sea and Gulf of Thailand, southeast of Myanmar (Burma). Geographically, Thailand has 76 provinces, which is subdivided into six regions namely, Northern, Southern, Eastern, Western, North Eastern (Isan) and Central. Each of these regions is quite different in terms of physical conditions, cultural and socioeconomic structures. The Central region has been the centre of the kingdom of Thailand. The data collection site for this study is Bangkok, which is the capital city of Thailand. The population of Thailand in 2010 stood at 67 million people but has slightly declined to approximately 66.7 million people in 2011 (CIA World Fact Book Thailand, 2011).

Thailand is the only Southeast Asian country never to have been colonized by Europeans or other world powers. Therefore, Thai is the predominant language but a combination of Thai dialects and distinct languages from countries along Thai borders are also spoken. Thailand's population is relatively homogenous with ethnic compositions of $75 \%$ Thai, $14 \%$ Chinese and $11 \%$ other. Thailand is an agricultural country with approximately half (49\%) working in agriculture related careers (Phantachat \& A-nan, 2009).

Traditionally, the family is the cornerstone of Thai society. Thai people respect hierarchical relationships (Knodel, 2009; Vorapanya, 2008). Social relationships are defined as one person being superior to the other. Parents are superior to their children and teachers to their students. Economic status and level of education of many Thai families often determine the type of school their children attend. These lead to equity and social justice issues. Services for poor children and those with disabilities are limited (Knodel, 2009). Chitchupong (2004) reported that, children located in the North-eastern region of Thailand, are considered relatively poor and account for roughly 2.9 million, do not have formal schooling and thus have limited opportunity to enter the labour force.

Buddhism is the predominantly practiced state religion among $95 \%$ of the population in Thailand alongside a minority of other world religions represented throughout the nation (Limanonda, 1995; Vorapanya, 2008). Buddhist ideals play a significant role in the societal organisation and practices. An important aspect of Buddhist faith which affects attitudes toward children with disabilities and additional needs is the belief in reincarnation. This belief holds that life does not begin with birth and end with death, but rather every person has several lives based upon the lessons of life not yet learned and the acts committed (karma) in previous lives can haunt the person in the next life (Vorapanya, 2008). Thai religious beliefs have far reaching implications for the organization of the education systems and how all children, particularly those with disabilities are perceived. For example, attitudes toward parents of children with disabilities remain negative as disability or additional need is viewed as (karma) - receiving punishments for their actions in a previous life (Fulk, Swerlik, Kosuwan, 2002). Additionally, 


\section{8 | Sunanta Klibthong}

many regulations regarding children's behaviour and etiquette are consequences of the Buddhist religion - children are subjected to authoritarian rules of adults (Vorapanya, 2008). Therefore, conceptualising and researching early childhood inclusive education in Thailand is important in understanding how the understanding, beliefs, and concerns of Thai early childhood teachers influence early childhood inclusion in totality.

\section{EDUCATION POLICY INITIATIVES}

There have been a number of national policy initiatives in Thailand in response to the growing concern that many children, particularly those from disadvantaged families, including those with disabilities are not benefiting from the changed social economic and educational outcomes thereby becoming more vulnerable. To this end the framework of education of children with disabilities in Thailand, the 1999 National Education Act was passed and revised in 2002. The Act mandated that all individuals should have equal rights and opportunities to receive basic education provided by the State for the duration of at least 12 years. Such education, provided on a nationwide basis, shall be of quality and free of charge (National Education Act, 1999).

The implementation of inclusive pilot programs shifted emphasis from special segregated schools to inclusive education (National Education Act, 1999) and in 2003, inclusion for special needs children was implemented in more public schools, primarily with partially sighted and partially hearing children (UNICEF, 2003). These developments have led to Thai children having more opportunities to access educational services and to engage in early childhood education.

The moves towards inclusive education reflected in policies considering every child as having the right to receive quality education and educational opportunities to enable full social and economic participation in society. It also includes the right to accept care and education for children who are underprivileged, handicapped, youth, women and the elderly (Office of Education Council, 2006; Vorapanya, 2008). The National Education Act also gave rights and opportunities to children with disabilities to receive free basic education specially provided by the state (Nation Education Act, 1999; Phantachat \& A-nan, 2009).

Although the policies demonstrate the government of Thailand's commitment to equity and social justice for all children, Thailand's education in the early years is still facing challenges in terms of achieving successful early childhood inclusive education for all children. In virtually all provinces in Thailand, the gap between enrolment of children with and without disabilities remains huge. Comparatively, the proportion of children in school system to school age population is $83.33 \%$ whereas statistic shows that children with disabilities' access to education are only $67.8 \%$ (Thailand Country Report, 
2007). A large proportion of children with disabilities are still not receiving educational services. Many children with disabilities who are included in the schools are "excluded within the classroom" (UNICEF, 2003, p. 50). One of the reasons given for the low enrolment is the insufficient number of schools that can accept children with disabilities (UNICEF, 2003). Besides, whether or not children with disabilities are accepted and fully included in schools depends very much upon the understanding, beliefs and attitudes of the teachers (Carter, 2006). Coupled with this it is the lack of qualified teachers in the field related to early childhood inclusive education that is a cause of concern. In terms of educational quality for young children, pedagogy remains punitive and teacher directed (Klibthong, 2011).

There is clear evidence that Thailand has taken great steps towards providing early childhood inclusive education for all children. This initiative included establishing child care centres in nearly all the country's provinces (Angeles-Bantista, 2004) however; some education experts in Thailand have confirmed that several cultural factors, including perceived norms and inherited beliefs lead to negative attitudes towards children with disabilities in early childhood education (Angeles-Bantista, 2004; Vorapanya, 2008).

\section{REVIEW OF RELATED LITERATURE}

Inclusive education has often been characterized by controversies with regard to definitions and what constitute its practice in schools. Several authors and researchers have defined the concept of inclusion differently. Although there are differences in definition, the central theme is social justice and equity (Agbenyega \& Deku, 2011; Ashman, 2012; Barton, 2010; Loreman, Deppeler \& Harvey, 2010; UNESCO, 2009). The concept of inclusion is seen as "a process of addressing and responding to the diversity in the needs of all children, youth and adults through increasing participation in learning, cultures and communities, and reducing and eliminating exclusion within and from education" (UNESCO, 2009, p. 8); all children being valued, accepted and respected regardless of ethnic and cultural backgrounds, socio-economic circumstances, abilities, gender, age, religion, beliefs and behaviours (Loreman, Deppeler \& Harvey, 2010); an ongoing process aimed at "offering quality education for all while respecting diversity and the different needs and abilities, characteristics and learning expectations of the students and communities, thereby eliminating all forms of discrimination" (UNESCO, 2008 , p. 3); and as a human right issue through which to remove barriers in society (Ainscow, 2005).

The Education For All Monitoring Report (2005) emphasized that "learning should be based on the clear understanding that learners are individuals with diverse characteristics and backgrounds, and strategies to improve quality should therefore draw on learners' knowledge and strength 
(UNESCO, 2009, p. 10). The pursuit of 'Education for All', involves engaging with questions of social justice, equity and participatory democracy which all people must have been empowered to have in society (Barton, 2010). This idea is supported by the Salamanca Statement on Principles and Framework for Inclusion which states:

Inclusive orientations are the most effective means of combating discriminatory attitudes, creating welcoming communities, building an inclusive society and achieving education for all" (UNESCO, 1994, p. ix).

With the notion of equity and social justice, contemporary philosophy of inclusion has moved beyond the narrow conception of disability and normality (Ashman, 2012; Swart \& Agbenyega, 2010, Loreman, Deppeler \& Harvey, 2010) to embrace a 'whole school approach to education' (see http:/ / www.wholeschooling.net) that demands equal attention be given to children in all educational settings to enable them to deal with constraints that inhibit developmental and learning outcomes. In this study inclusion is conceptualised as a process of supporting all children to be able to negotiate and manage their life courses through effective participation in education.

Inclusive education in contemporary society demands from educators to go beyond rhetoric and educational superficiality because; every child has a fundamental right to education, and must be given the opportunity to achieve and maintain an acceptable level of learning; every child has unique characteristics, interests, abilities and learning needs; education systems should be designed and educational programmes implemented to take into account the wide diversity of these characteristics and needs, (UNESCO, 1994, p. viii).

This position is reiterated by UNESCO at the Dakar Framework for Education for All(2000) that:

Inclusive education' has emerged in response to a growing consensus that all children have the right to a common education in their locality regardless of their background, attainment or disability. The Framework stressed the goal of meeting the learning needs of all young people and adults... inclusion... challenges all exclusionary policies and practices in education as they relate to curriculum, culture and local centres of learning. Instead of focusing on preparing children to fit into existing schools, the new emphasis focuses on preparing schools so that they can deliberately reach out to all children (UNESCO, 2000, p. 18).

Early childhood inclusive education is a process of giving children the opportunity to co-construct knowledge with teachers (Agbenyega, 2011). It is based on the philosophy that what children learn and how they learn, is governed by their cultural background, where they live as well as teachers' values and institutional practices (Ashman, 2012). Early childhood inclusion embodies "the values, policies, and practices that support the right of every 
infant and young child and his or her family, regardless of ability, to participate in a broad range of activities and contexts as full members of families, communities and society" (Allen \& Cowdery, 2012, p. 7). This means inclusive early childhood education is not only about enrolling children to attend preschool programs, childcare or recreational programs; it is about accepting and valuing human difference, including the provision of the necessary support for all children and families to fully participate in the programmes of their choice, which ensures that all children's needs are met (Allen \& Cowdery, 2012). Therefore, the key aspect of early childhood inclusion is about values, and beliefs and institutional practices that work best for each child. In this sense, inclusive early childhood is for all children with and without disabilities who are part of society, and therefore must receive equal attention and participate in meaningful and quality education, and care within communities (Guralnick, 2001; Tsao et al., 2008).

It is about supporting typically developing children and children with additional needs to participate fully in a program or service that caters for all children. This means inclusion focuses on the transformation of school cultures and pedagogy to increase access to all children, enhance the acceptance of all students, maximize children participation in various activity, and increase the achievement of and development of all children (Booth, Ainscow, BlackHawkins, Vaughan, \& Shaw, 2000; Kalambouka, Farrell, Dyson, \& Kaplan, 2005).

Previous research has shown that disability severity, disability type, and teacher's previous experience determine the nature of teacher attitude towards inclusive education (Cambell, Gilmore, \& Cuskelly, 2003; Foreman, 2007; Kemp \& Carter, 2005). However, professional development was found to contribute to altering teachers' negative attitude and concern about inclusive practice (Agbenyega, 2007; Loreman, Deppeler \& Harvey, 2010). Silverman (2007) points out that beliefs, concerns and attitudes of teachers directly shape the ways they work with children which have a great influence on classroom environment and children's outcomes.

The concern for quality early childhood education for all children has focused attention on inclusive education as a way of ensuring marginalised children in Thailand also receive equal attention in education. It is clear the concept of inclusive education in early childhood is gaining support in Thailand education system. However, as inclusion is a relatively new concept, barriers exist which need to be identified and overcome to make early childhood inclusive education practicable. A key barrier is the lack of knowledge and training in inclusive education (Vorapanya, 2008). The Office of the National Education Commission (ONEC, 2009) in Thailand, reported that teachers within inclusive education classrooms do not have sufficient background knowledge to teach all children effectively. Other studies on 
inclusive education in Thailand suggest that many teachers feel anxious and resentful when working with children with disabilities in inclusive classroom (Shippen, Crites, Houchins, Ramsey \& Simon, 2005; Vorapanya, 2008). In another study some Thai teachers noted that they did not know how to handle problems and organize lessons and activities for children with special needs (Kantavong \& Sivabaedya, 2010).

Previous inclusive research in Thailand showed teachers were apprehensive that children with disabilities would add difficult burdens to their work because they have not been trained in disability related courses (Umpanroung, 2004). Feny de Los Angeles-Bantista (2004), researching for UNESCO on early childhood inclusion quality in Thailand also concluded that the main issues confronting early childhood inclusive programs are traceable to cultural beliefs and teaching quality. Others found that Thai families, particularly those who are poor or live in rural areas are less likely to be aware of existing inclusive programs or to have the willingness and means to access those services (Fulk, Swerlik, \& Kosuwan, 2002). A Voluntary Services Overseas (VSO) research that surveyed inclusive practices in Thailand also found mixed understandings of the concept of inclusion and traditional didactic pedagogical practices that exclude many children from full participation in their learning (Haikin, 2009). Vorapanya (2008) completed a study on best models for inclusion in Thailand and found school administrators in Thailand to have little knowledge about appropriate inclusion practices. However, the study did not include classroom teachers in the research design, therefore missing important data on teacher attitudes, beliefs and concerns.

International research on inclusive practice also document barriers to inclusion which are similar to those found by previous researchers in Thailand. A vast majority of regular teachers, although they teach large class sizes, do not have assistants (Agbenyega, Deppeler, \& Harvey, 2005; Forlin, 2008; Salend, 2008). Other barriers relate to the lack of confidence in teacher's abilities or experiences to modify instruction for diverse children in inclusive environments (Eleweke \& Rodda, 2002; Rose, 2001; Stough, 2003; UNICEF, 2003). Early childhood inclusive education is based on a value and belief system that invites, celebrates and supports all children no matter their nature, nationality, class, gender, language, socio-economic background, cultural origin or ability (Swart \& Pettipher, 2005).

\section{RESEARCH QUESTIONS}

Through the review of the literature and the problem the following research questions emerge:

i. What is early childhood teachers' understanding of inclusion? 
ii. What are their beliefs and concerns regarding the inclusion of young children with disabilities in early childhood programmes in Thailand?

\section{METHOD}

A plethora of researchers have argued that research methodology of a study must be consistent with the questions and purpose of the investigation (Newman \& Benz, 1998; Onwuogbuzie \& Leech, 2006; Tashakkori \& Teddlie, 1998). The purpose of this study is to explore early childhood teachers' understanding of inclusion, beliefs and concerns about including young children with disabilities in early childhood programmes in Thailand. The study adopted a qualitative approach of group discussions to gather data from nine early childhood teachers selected from one large preschool enrolling 255 children aged 2-6 years in Bangkok, the capital city of Thailand. The kindergarten was selected because of the commitment of the school authorities to implement inclusive education. All the nine teaching staff volunteered and participated in the study. Data were gathered through group discussion which lasted for three and a half hours. Discussions were tape recorded with permission from the teachers and played back to them the following day when the children had all gone home after school. The teachers also asked for the transcripts of the data and endorsed their comments before it was finally analysed. Using a framework analysis, the following steps, familiarization; identifying a thematic framework; indexing; charting; and mapping and interpretation (Ritchie \& Spencer, 1994) were followed to analyse the data.

The findings point to basic conceptualisation of inclusion with beliefs and concerns related to three important themes: cultural and religious issues, training issues and type of disability as the main barriers to inclusive education of young children. Because a purposeful sampling approach was used and the number of participants was small this study does not claim generalizability, however, the sample provided useful information for snapshot discussions of the research questions and implications for moving beyond rhetoric (Creswell, 2005).

\section{FindiNGS AND DiscUSSIONS}

Question One: What is early childhood teachers' understanding of inclusion?

Regarding this question, all the nine preschool teachers provided basic explanations to inclusive education. They perceived inclusion as educating children with and without disabilities together in one setting. None of the teachers mentioned quality teaching, human right or social justice in their definition. 


\section{4 | Sunanta Klibthong}

When you bring the children who have disabilities to learn with their friends then you are doing inclusion...children with disabilities don't need to come always but it is good for them to have some experience with the other children...inclusive education hmm...when you allow children with disabilities to attend your class... when children who are disabled also attend the same school it is inclusion...I believe... it is about educating children with disabilities together with the other children.

Concepts are very important because they lead to the understanding of the components of that particular construct which can then be transformed into better practice. However, the teachers' concept of inclusion as revealed in this study is quite simplistic and lacked the rudiments of international perspectives on inclusion as human right, social justice and educational quality. It is argued in the international literature that inclusion is an ongoing process aimed at "offering quality education for all while respecting diversity and the different need and abilities, characteristics and learning expectations of the students and communities, thereby eliminating all forms of discrimination" (UNESCO, 2008 , p. 3); and as a human right issue through which to remove barriers in society (Ainscow, 2005). This comprehensive and far-reaching view of inclusion is important for protecting vulnerable children in all societies and ensuring that schools respond to their diverse needs instead of expectation from the children to adjust to schools. When teachers conceptualise inclusive narrowly they may develop limited capacity to transform schools to respond to the diverse needs of all children (Eleweke \& Rodda, 2002; Rose, 2001; Stough, 2003; UNICEF, 2003). It is therefore important that rudiments of inclusive education are well understood and should form the basis for all activities towards the implementation of inclusion.

Question Two: What are the beliefs and concerns regarding the inclusion of young children with disabilities in early childhood programmes in Thailand?

\section{BELIEFS}

The findings of this study show that the beliefs held by the teachers regarding inclusive education of children with and without disabilities were mixed. Some of the views expressed by the teachers relate to the issue of reincarnation, which they feel are responsible for disabilities.

Definitely, if a family did something wrong in previous life it has effect on young children... positive or negative effect depending on people around them... if children did something wrong, it will affect their lives in another life which can be a kind of disability... I believe that if children did something wrong, it definitely affect them in the next life.

This finding is interesting because it appears little has changed in belief systems regarding re-incarnated children with disabilities or the idea that 
some children's current state is the result of a previous life experience. This finding is consistent with other large scale studies which documented similar belief systems (Fulk, Swerlik, \& Kosuwan, 2002; Haikin, 2009; Vorapanya, 2008). Despite these kinds of beliefs the teachers were generally positive about inclusive education.

Inclusive classrooms are good for children with and without disabilities in many ways because children with disabilities can develop their social skills and other forms of adaptive behaviour from their peers in inclusive classrooms...they also benefit from children without disabilities as well because children without disabilities can help those with disabilities and increase responsibility in the classroom... Inclusion will support children with disabilities to develop social skills; it is good for them because they have opportunities to participate with other children apart from their family...As for me I support inclusive education because children with disabilities can develop their skills, they have their peers to be a role model.

Other studies found similar trends that many teachers are generally aware of the benefits of inclusive education for students with and without disabilities but when it comes to practice teachers who are not well prepared or lacked innovative skills regress into negative attitudes and turn to resent inclusive education (Ainscow, 2005; Eleweke \& Rodda, 2002; Rose, 2001; Stough, 2003).

\section{CONCERNS}

Although all the nine teachers who participated in this study support inclusive education of young children with and without disabilities they expressed several concerns as significant barriers to successful early childhood inclusion in Thailand.

It is not easy to do inclusion... we should pay more attention to class size... if the classroom has only one teacher, she may not be able to look after all the children in the classroom...inclusive classrooms should have more than two teachers to look after children...some children with disabilities may exhibit unacceptable behaviour to each other. In my opinion, school should provide one to one teacher for children with disabilities...

As in the findings of this study, class size and its implication for managing behaviour problems in inclusive classrooms have been consistently documented in several other studies (Agbenyega, Deppeler, \& Harvey, 2005; Forlin, 2008; Salend, 2008). It is surprising to find that the average class size of the kindergarten in which this study took place is 32 children to one teacher. It is not possible how inclusive education could be practicable in such learning environment that includes children with disabilities. It appears class size issues have not received the needed attention in many developing countries, including Thailand. This is a serious concern that must be addressed. Other concerns expressed by the teachers relate to how other children perceive the way children with disabilities behave, and the kinds of support they receive. 
They were concerned that insufficient information to other children about those with disabilities would bring various consequences leading to inappropriate inclusive practices.

We should realize some consequences to children without disabilities as well because children without disabilities may not have sufficient understanding between children with typically developing and children with additional needs...Children might questions in their mind why this child has different behaviour from their peers, why teacher pay more attention to him or provide less work than other children. Therefore, parents and teachers should clear explanation and talk to other children..., which would lead to greater acceptance, respect and value of children who are different.

Previous research supported this same issue that a better understanding of disability enables both children and teachers to develop positive attitudes and accept them in inclusive classrooms (Ainscow, 2005; Forlin, 2008; Kantavong \& Sivabaedya, 2010). In addition, some of the teachers felt that the child with a disability must be ready before they access inclusive education. They were more in favour of children with mild disabilities accessing inclusive education and think that those with severe disabilities be separated into special classes. Reasons given for this are the lack of knowledge and time needed to spend on children with severe disabilities.

In my opinion, if children with disabilities are ready, they can learn with children without disabilities in the same classroom. Furthermore, teacher should understand and encourage children with disabilities to participate in activity, which challenges their ability...I think it is good for children with mild disabilities because it help them to live with other people in real society. However, children with severe disabilities, I think, teacher should separate them from those without disabilities because it will add a burden to teacher's work. Teacher has inadequate knowledge and time to manage the class and prepare for the lesson. Teacher has to spend a lot of time for children with disabilities...Children may not obtain enough knowledge in the classroom.

The teachers' concerns reflect the inherent complexities of inclusive education. To a large extent, inclusive practice is not linear; it is a dynamic process that involves different actors and components. Time is a necessary component and so is the way other children without disabilities perceive their peers with disabilities. Teachers will continue to ask for separation between children with severe disabilities from those without disabilities if they lacked the required skills, knowledge, time and resources to do their job (Kantavong \& Sivabaedya, 2010). To make inclusive education successful teachers need specific knowledge on child development and skills in flexible teaching methods (Shippen, Crites, Houchins, Ramsey \& Simon, 2005; Vorapanya, 2008). If teachers cannot develop flexibility in the ways they teach children, inclusion becomes an abstract ideology as indicated by the teacher participants. 
It is difficult for teacher to teach children with and without disabilities together in the pre-school because teacher has to balance teaching methods for both children with and without disabilities. Teacher has to know so many things such as child development, appropriate environment for all children. The main problem is we have not been train to teach children with and without disabilities...

The above statements from the teachers are an important finding establishing the professional needs of the teachers. I argue that nobody is put in front of a driving wheel to drive a car without receiving the appropriate training. Doing so endangers the lives of the driver, passengers as well as passers-by. Similarly, placing early childhood teachers in inclusive classrooms and expecting them to deliver successful inclusion without the necessary training and support is not only ideologically wrong but constitutes a violation of the teachers' and children's rights. It would lead to disastrous results.

\section{RECOMMENDATIONS FOR IMPROVING EARLY CHILDHOOD INCLUSIVE EDUCATION IN THAILAND}

The findings of this small case study has identified many topical issues with serious implications for successful inclusive education of young children in Thailand and globally. The study reflects the vital information that the teachers share when asked for their perspectives on their early childhood inclusive school experiences. The teachers have expressed that effective inclusive education is comprised of knowledge about child development and disability, small class size and established support systems from all actors of education. It also established that the teachers had basic understanding of inclusive education as placing children with and without disabilities together in one class. Although there appears to be overwhelming support for inclusion because of its benefits, traditional religious attitudes still dominate the teachers' thinking regarding the nature and causes of disability. In view of these findings the following implications for improving inclusive early childhood inclusive education in Thailand are made.

The study established training needs related to the causes of various disabilities, curriculum modification and management of disability. It is therefore important for preschool proprietors and directors to provide paid inservice professional development for teachers on the causes of disability. The training must include discussions on the rich Thai culture and religious beliefs and what can be used from them to transform schools. This could be done by allowing open discussions regarding disability, culture and religion in schools and community forums. The training should also involve children without disabilities taking support roles or as child mentors for those with disabilities. It is also important to engage the teachers in deeper discussions about the concept of inclusion beyond the current notion of merely placing children with 
and without disabilities together in one classroom. Conceptual clarity is urgently needed to think of inclusion as a moral and ethical practice that celebrates difference and respects the rights of each individual child because the deeper the understanding of inclusion the better the practice. If ambiguous definitions of inclusive education continue to exist with teachers, the design and implementation of inclusion will be compromised.

Furthermore, learning about culturally responsive instruction is an important way to develop a learner-centred model. This would assist teachers to learn to organize the curriculum and instructional practices that meets the learning needs of diverse children in preschools. It is also important for the Thailand Ministry of Education to move swiftly towards increasing the teacher workforce and consequent reduction in teacher - child ratios, particularly in the early years. This should be supported by effective legislation that is rigorously monitored.

\section{CONCLUSION}

This study, although small, has opened another window of opportunity for more research in this area in order to evaluate inclusive educational practices in urban and remote early childhood programs in Thailand. To do so effectively requires incorporating the perspectives of children, families, teachers and policy makers. It is useful to build a comprehensive knowledge base with multiple viewpoints about what is working and what is not and why. Inclusive education, particularly at the early years level is complex but very crucial and unless thoughtful efforts are made to build interconnection and pursue planned efforts, conceptual confusion, concerns, different beliefs and practices would lead to dispersion and scatter the gains of inclusive education. A classroom community-based inclusion is critically important to pursue programs of successful inclusion in the early years, and to get to where we want inclusion to take us we need to transform our thinking, belief systems and practices.

\section{REFERENCES}

Agbenyega, J. S., Deppeler, J., Harvey, D. (2005). Attitudes Towards Inclusive Education in Africa Scale (ATIAS): An Instrument to measure teachers' attitudes towards inclusive education for students with disabilities. Journal of Research and Development in Education, 5, 1-15.

Agbenyega, J. S. (2007). Examining teachers' concerns and attitudes to inclusive education in Ghana. International Journal of Whole Schooling, 3(1), 41-56.

Agbenyega, J. S. (2011). Institutional practices in early childhood teachers' construction and management of learning spaces: an encounter for 
inclusion or exclusion? International Journal of Equity and Innovation in Early Childhood, 9(1), 62-76.

Agbenyega, J., \& Deku, P. (2011). Building new identities in teacher preparation for inclusive education in Ghana. Current Issues in Education, 14(1), 1-36.

Ainscow, M. (2005). Looking to the future: Towards a common sense of purpose. Australasian Journal of Special Education, 29(2), 182-186.

Allen, E., \& Cowdery, G. E. (2012).The exceptional child: Inclusion in early childhood education. Belmont, CA: Wadsworth, Cengage Learning.

Angeles-Bantista, F. (2004). Early Childhood Care and Education in South - East Asia:Working for Access, Quality and Inclusion in Thailand, the Philippines and Viet Nam. UNESCO.

Ashman, A. (2012). A culture of inclusion. In A. Ashman \& J. Elkins (Ed.). Education for inclusion and diversity (4th ed.). (pp. 1-33), French Forests, NSW: Pearson.

Barton, H. (2010). Strengthening the roots of planning. Planning Theory $\mathcal{E}$ Practice, 11(1), 95-101.

Booth, T., Ainscow, M., Black-Hawkins, K., Vaughn, M., \& Shaw, L. (2000). Index for inclusion: Developing learning and participation in schools. Bristol, England: Centre for Studies on Inclusive Education.

Cambell, J., Gilmore, L., \& Cuskelly, M. (2003). Changing student teachers' attitudes towards disability and inclusion. Journal of Intellectual and Developmental Disability, 28(4), 369-379.

Carter, S. (2006). The development of special education services in Thailand. International Journal of Special Education, 21(2), 32-36.

Chitchupong, N. (2004, November). Access to education of poor children and youth in Thailand. Paper presented at the meeting of the Thai Population Association, Bangkok, Thailand.

CIA World Fact Book Thailand. (2011). Thailand people 2011. Retrieved from http://www.theodora.com/wfbcurrent/thailand/thailand_people. html

Creswell, J. W. (2005). Educational research: Planning, conducting, and evaluating quantitative and qualitative research (2nd ed.). Upper Saddle River, NJ: Pearson Education.

Eleweke, C. J., E Rodda, M. (2002). The challenge of enhancing inclusive education in developing countries. International Journal of Inclusive Education, 6(2), 113-126.

de los Angeles-Bautista, F. (2004, October). Early childhood care and education in South-East Asia: Working for access, quality and inclusion in Thailand, the Philippines and Vietnam. Bangkok: Thailand.

Foreman, P. (Ed). (2007). Inclusion in action. Victoria: Thomson. 
Forlin, C. (2008). Education reform for inclusion in the Asia-Pacific region: What about teacher education? In Forlin, C. and Lian, Ming-Gon John (eds.) (2008) Reform, inclusion and teacher education: Towards a new era of special education in the Asia-Pacific region. London: Routledge.

Fulk, B. M., Swerlik, P. A., \& Kosuwan, K. (2002). Special education in Thailand: Teaching Exceptional Children, 73.

Guralnick, M. J. (2001). A framework for change in early childhood inclusion. In M. J. Guralnick (Ed.), Early childhood inclusion: Focus on change. (pp.3-35). Baltimore: Brookes.

Haikin, M. (2009). Survey of inclusion. Voluntary Services Overseas (VSO). Author.

Kalambouka, A., Farrell, P., Dyson, A., \& Kaplan, I. (2005). The impact of population inclusivity in schools on student outcomes. In Research Evidence in Education Library. London: EPPI-Centre, Social Science Research Unit, Institute of Education, University of London.

Kantavong, P., \& Sivabaedya, S. (2010). A professional learning program for enhancing the competency of students with special needs. International Journal of Whole Schooling. 6(1), 53-62.

Kemp, C., \& Careter, M. (2005). The contribution of academic skills to the successful inclusion of children with disabilities. Journal of Developmental and Physical Disabilities. 18(2), 123-147. doi: 10.1007/s10882-006-9010-z

Klibthong, S. (2011). Teacher-child interaction in early literacy development: A case study in Thailand (Master's thesis). Monash University, Melbourne, Victoria, Australia.

Knodel, J. (2009, June). Is intergeneration solidarity really on the decline? Cautionary evidence from Thailand. Seminar on Family Support Networks and Population Ageing, Doha.

Limanonda, B. (1995). Families in Thailand: Beliefs and realities. Journal of Comparative Family Studies, 26(1), 67.

Loreman, T., Deppeler, J. \& Harvey, D. (2010). Inclusive education: supporting diversity in the classroom. New York, NY: Routledge.

National Education Act, (1999). National Education Act of B.E.2542. Retrieved June 1, 2005, from http:/ / www.moe.go.th/English/edu-act.htm.

Newman, I., \& Benz, C. R. (1998). Qualitative-quantitative research methodology: Exploring the interactive continuum. Carbondale: Southern Illinois University Press.

Office of the Educational Council, the Ministry of Education Kingdom of Thailand. (2006). Education in Thailand 2005/2006. Bangkok, Thailand: Office of the Educational Council.

Office of the National Education Commission (ONEC). (2009). Summary report: 
9 years of educational reform (1999-2008). Bangkok: VTC Communication Ltd.

Onwiegbuzie, A. J., \& Leech, N. L. (2006). Linking Research Questions to Mixed Methods Data Analysis Procedures. The Qualitative Report, 11(3), 474498.

Phantachat, W., \& A-nan, C. (2009). The Second Regional Workshop on the Enhancement of Information and Communication Technology (ICT) Accessibility for Persons with Disabilities. Incheon, Republic of Korea.

Reay, D. (2006). The Zombie Stalking English Schools: Social Class and Educational Inequality. British Journal of Educational Studies, 54(3), 288307.

Ritchie, J., \& Spencer, L. (1994). Qualitative data analysis for applied policy research. In A. Bryman and R. G. Burgess (eds.). Analyzing qualitative data (pp.173-194). London: Routledge.

Rose, R. (2001). Primary school teacher perceptions of the conditions required to include pupils with special education needs. Educational Review, 53(2), 147-156.

Salend, S. J. (2008). Creating inclusive classrooms: Effective and reflective practices $\left(6^{\text {th }}\right.$ ed.). Columbus, $\mathrm{OH}$ : Merrill/Pearson Education.

Shippen, M. E., Crites, S.A., Houchins, D. E., Ramsey, M. L., \&Simon, M. (2005). Preservice teachers' perceptions of including students with disabilities. Teacher Education and Special Education, 28(2), 14-21.

Silverman, J. C. (2007). Epistemological beliefs and attitudes toward inclusion in pre-service teachers. Teacher Education and Special Education, 30(1), 42-51.

Stough, L. M. (2003). Special education and severe disabilities in Costa Rica: Developing inclusion in developing country. Research and Practice for Persons with Severe Disabilities, 28(1), 7-15.

Swart, E., \& Agbenyega, J. (2010). Developing researcher self-reflexivity and agency: across-cultural narrative of inclusive education research. Paper presented at the Australian Association for Research in Education (AARE) 2010 International Education Research Conference $\mathrm{M}$ e $1 \mathrm{~b}$ o u r n e, A u s t r a l a . R e t r i e v e d from:http://ocs.sfu.ca/aare/index.php/AARE/AARE_2010/paper /view/2104

Swart, E., \& Pettipher, R. (2005). A framework for understanding inclusion. In E. Landsberg, D. Kruger and N. Nel (Eds.), Addressing barriers to learning. A South African perspective. Pretoria: VanSchaik. pp. 3-23.

Tashakkori, A., \& Teddlie, C. (1998). Mixed methodology: Combining qualitative and quantitative approaches (Applied Social Research Methods, No. 46). Thousand Oaks, CA: Sage.

Thailand Country Report. (2007). Country profile: Thailand. Retrieved from 
http:/ /lcweb2.loc.gov/frd/cs/profiles/Thailand.pdf

The United Nations (1989). Convention on the rights of the child Retrieved June 29, 2007, from http:/ / www.ohchr.org/englishllaw/pdf/crc.pdf

Tsao, L., Odom, S., Buysse, V., Skinner, M., West, T., \& Vitztum-Komanecki, J. (2008). Social participation of children with disabilities in inclusive preschool programs: Program typology and ecological features. Exceptionality, 16, 125-140.

Umpanroung, C. (2004). The administration of inclusive schools in Aangthong Province. Master' thesis, Rajapat Pranakornsriayuthaya University, Pranakornsriayuthaya, Thailand.

UNESCO. (1994). The Salamanca Statement and Framework for Action on Special Needs Education: Access and Quality. Paris: UNESCO

UNESCO. (2000). EFA global monitoring report. Paris: Author.

UNESCO. (2000). The Dakar Framework for Action, Education for All: Meeting our Collective Commitments. Paris: UNESCO.

UNESCO. (2008). Equity and Inclusion in Education. Paris, UNESCO (unpublished).

UNESCO. (2008). The Role of Early Childhood Education for a Sustainable Society: Paris: Author.

UNESCO. (2009). Policy guidelines on inclusion in education. Paris, UNESCO.

UNICEF. (2003). Inclusive Education Initiatives for children with disabilities: Lesson from the East Asia and Pacific Region. Bangkok, UNICEF. Press.

Vorapanya, S. (2008). A model for inclusive schools in Thailand. A thesis Presented to the Department of Educational Leadership and the Graduate School of the University of Oregon in partial fulfilment of the requirements for the degree of Doctor of Philosophy. 